\title{
LEO KESSLER E SUA ÓPERA "PAPILIO INNOCENTIA"
}

\author{
Luiz Heitor Corrêa de Azevedo \\ Rio
}

\section{Preâmbulo}

Lembrado com respeito na terra de adoção por uma elite o'e intelectuais e artistas que êle havia cativado com o seu dinamismo e sólidos predicados profissionais e morais, Leo Kessler deixou sua passagem assinalada na história local da cidade de Curitiba, onde viveu 13 anos, pelo espirito empreenởedor que o animava e por uma infatigável atividade. No $35 .^{\circ}$ aniversário de seu passamento êste estudo é dedicado à memória do inditoso artista suíço que elegeu nossa terra para viver, e nossas águas para morrer.

\section{Fontes}

Por ocasião de uma visita a Curitiba, em 1957, pude procurar a viuva do compositor, D. Rosa Amália Bengtsson Kessler, e sua filha, Dona Dorotéa Kessler Ferreira, que muito amàvelmente puseram à minha đ̛isposição o arquivo de família, permitindo-se compulsar partituras, documentos, recortes de jornais, graças aos quais me foi possível conhecer mais profundamente a música e as várias etapas da existência infelizmente tão breve de Leonardo Kessler. Essa documentação e os depoimentos e notícias reunidos por Jaime Balão no opúsculo que consagrou ao compositor, com a colaboração de Andraởe Muricy (1), tornaram possível a redação dêste trabalho.

(1) Leo Kessler. Curitiba, 1926. 
Referências à atividade de Leo Kessler encontram-se, também, nas obras de Vincenzo Cernicchiaro (2), Renato Almeida (3) e em meu livro 150 Anos de Música no Brasil (4).

\section{Nascimento e família}

Leo Kessler nasceu em Schiers, no cantão dos Grisões, a 12 de setembro de 1882. Seu pai, Frederico Kessler, homem de condição modesta; se impôs os mais severos sacrifícios para assegurar a educação musical đo jovem Leonardo, que tal era o seu nome de batismo. Em 1924, Andrade Muricy, amigo e discípulo de Leo Kessler, então fazendo uma estação de cura em Arosa, nos Alpes Réticos, teve ocasião de conhecer Frederico e um avô ơo nosso múşico. "Encontram-se aqui bem próximos, robustos e rijos como os pinheiros centenários que aromatizam êstes ares vivificantes", diz êle, na Memória enviada à Academia de Letras do Paraná e lida em sessão pública a 7 de janeiro de 1925 (5). A mãe já havia morriơo, em 1906.

A eáucação de Leo Kessler foi a de um pequeno suíço que os pais desejam tornar um bom cidadão, útil ao seu cantão e à federação. Suas disposiçōes intelectuais e artísticas abriram-lhe o caminho dos estudos superiores e do Conservatório. Depois de haver freqüentado a escola primária, ingressou, em 1896, no Instituto Educacional de Schiers, cursando com brilhantismo êsse estabelecimento até 1901, quando o Pequeno Conselho Cantonal the conferiu o Diploma de professor ởe primeira classe. Ao lado da formação básica havia recebido liçōes de música, entreganơo-se com ardor ao estu-

(2) Vincenzo Cernicchiaro, Storia della musica nel Brasile dai tempi coloniali sino ai nostri giorni (1549-1925). Milano, Stab. Tip. Edit. Fratelli Riccioni, 1926, p. 605.

(3) Renato Almeida, História da Música Brasileira. Segunda ediçăo correta e aumentada com 151 textos musicais. Rio de Janeiro, F. Briguiet \& Comp., editôres, 1942, p. 418.

(4) Lijiz Heitor, 150 Anos de Música no Brasil (1800-1950). Rio de Janeiro, Livraria José Olympio Editôra, 1956, p. 213.

(5) Essa Memória se acha publicada no opúsculo já citado, p. 23. 
do do piano, num velho instrumento comprado pelo pai. Logo "superou o seu professor", diz Frederico Kessler em carta que a 23 de outubro de 1925 enviou a Jaime Balão, e se acha publicada no já mencionado opúsculo em memória ào filho (6).

Em 1900 o adolescente fôra obrigado a interromper temporàriamente os estudos. Tinha então 18 anos e uma grave depressão nervosa o impedira de freqüentar as aulas do Seminário. Mas, cedo restabelecido, conseguira submeter-se, com êxito completo, aos exames daquele ano.

A família teria preferido que o jovem Leo se deixasse ficar em Schiers, entregue à carreira do magistério (7); mas êle tinha outras aspirações; sentia-se atraído pela Música e pela Aventura. Naquele mesmo ano de 1901, em que concluíra seus estudos em Schiers, parte para o estrangeiro. Em Estrasburgo aceita o cargo de professor num orfanato, que the deixava lazeres bastantes para freqüentar o Conservatório d'e Música e a Universidade. Até 1904 permanece nessa cidade, então alemã, onđe completa o curso do Conservatório com distinção, senòo aluno de órgão de Ernesto Münch, pai do famoso regente da orquestra de Boston, Carlos Münch. Na Universidade, além de outras classes, segue as de História da Música, professadas por Gustavo Jacobsthal.

Depois de Estrasburgo, Paris. Desta vez o pai teve de ajudá-lo financeiramente, o que fêz com sacrifício (mas também com íntima satisfação. Levantou um empréstimo para poder fazer face às despesas. Leo Kessler mais tarde, quando começou a ganhar sua viởa, restituiu-lhe a soma então recebida. Em Paris foram seus mestres Isidoro Philipp, também professor de Guiomar Novais, para o piano, e o aristocrático organista Carlos Maria Widor, para o seu instrumento e a Composição. A estadia do jovem Kessler em Paris,

(6) P. 6 .

(7) "Muito gostaríamos que tivesse ficado aqui em seu torrāo natal, aceitando uma vaga de professor, a fim de auxillar-nos, do que muito careciamos, diz o pai, na carta já citada, dirigida a Jaime Baläo (p. 7). 
entretanto, não podia ser longa, pois estava limitaỏa pelas suas parcas disponibilidades orçamentárias. Era preciso que êle se lançasse à vida profissional, para fazer render os conhecimentos que até então acumulana, conscienciosamente, com tanta seriedade. Em 1906 vamos encontrá-lo no exercício de suas primeiras funções de natureza musical. Nesse mesmo ano faz uma visita a Schiers, para assistir aos funerais da mãe, e consolar o pai de tão đuura perda.

\section{Atividades musicais na Europa}

De 1906 a 1908 ocupa o pôsto de terceiro regente e ensaiador do Teatro de Riga, onde várias vêzes teve ocasião ởe assumir a direção dos espetáculos e de fażer ouvir, nos concertos que dirigia, composiçōes sinfônicas de sua autoria.

Nesse último ano exerce, também, as funções de ensaiađơr no Teatro da ópera Cômica de Berlim, por umas poucas semanas. Mas parece que o trabalho não foi de seu agrado e êle retoma, por mais algum tempo, suas funções em Riga.

Em 1909 encontramo-lo dirigindo . ópera e opereta no Teatro de Flensburgo, e durante a temporada de 1910-1911 em Czernowits, no Império Austro-Húngaro. Teve também a oportunidade de aparecer dirigindo companhias itinerantes em várias cidades da Alemanha, como Magdeburgo, Brunswick, Dortmund. O Oberon, de Weber, o Rigoletto, de Verdi, a Carmen, de Bizet, operetas como Orphée aux enfers, de Offenbach, Der Zigeunerbaron, d’e João Strauss, Ein Walzertraum, de Oscar Strauss, Gasparone, de Millöcker, Die Dollarprinzess, de Leo Fall, Donnerwetter tadellos, de Paulo Lincke, foram, entre várias outras, partituras que êle dirigiu durante êsse perioơo.

Essa fase da existência de Kessler, sobretudo em Riga, onde teve posição mais estável, foi assinalada pela composição de diversas obras, algumas das quais editaởas, como a Valse de concert, para piano, página brilhante no estilo de 
Moritz Moszkowski.

\section{No Brasil}

Havendo terminado seu contrato com o teatro de Czernowitz no comêço do ano de 1911, Leo Kessler aceitou a direção musical da Companhia de Operetas Alemãs Papke, que se preparava para visitar o Chile, a Argentina e o Sul do Brasil. Embarcou em março, para cruzar o Atlântico, e poucos meses depois veio parar em Curitiba, última etapa da excursão, onde devia ficar residindo. A Companhia Papke, com efeito, aqui se ơissolveu, e alguns de seus elementos permaneceram em Curitiba, atraídos pela amenidade do clima, pela fisionomia metropolitana progressista e pelas perspectivas de atividaờe profissional que poderiam encontrar. Na América do Sul a dissolução de companhias teatrais empenhadas em tournées aventurosas sempre foi, desde tempos imemoriais, uma das fontes que alimentaram a vida artística local, trazendo-lhe novos elementos cuja influência, por vêzes - e êsse é o caso de Kessler - chegou a ser prepondierante. Muitos dêsses artistas europeus atirados ao nomadismo de temerárias excursões pelas duras exigências do ganha-pão, preferiam, efetivamente, optar pela estabilidade de uma existência menos brilhante, mas também menos arriscada, em países em que a carência de profissionais lhes oferecia possibilidades de um futuro mais tranqüilo e mais útil à comunidade. Jorge Vucherpfennig, tenor da Companhia Papke, também ficou no Brasil e estêve associado a algumas das iniciativas artísticas deviơas ao espírito empreendedor de Kessler.

Leo Kessler era então um jovem de 28 anos, "de fisionomia insinuante e olhar vivo e penetrante" (8), "de uma amabilidade sem reservas" (9); essa foi a impressão que dêle guardou Jaime Balão, a quem Augusto Stresser, um dos primeiros amigos de Kessler, em Curitiba, apresentara o recém-chegado. Jaime Balão, autor do libreto da ópera Sidéria.

(8) Op. cit., p. 45 .

(9) Op. cit., p. 11. 
que seu primo Augusto Stresser musicara, desde logo se contou, também, entre os primeiros amigos brasileiros do músico suíço; foi seu colaborador e último confidente. "Dentro de poucos dias éramos amigos, entrelaçados os corações e os espíritos, não mais por simples afinidade espiritual - diz êle - mas por verdadeiros e fortes laços de amizade, que se deviam apertar e consolidar cada vez mais, cada dia que passasse" (10).

A seu pai, Kessler escrevia dizendo que preferia ficar no Brasil (11), o que era para o velho Frederico uma triste notícia, pois nunca mais devia rever o filho. A guerra de 1914-1918 , o casamento com uma brasileira, o nascimento da filha, e o prematuro desaparecimento do artista impediram-no, efetivamente, de empreender a viagem que sempre tivera desejo de fazer, um ơia, para visitar a família e banhar-se, de novo, na estimulante vida artística do Velho Continente. Em 1911 Kessler tinha deixado a Europa para sempre; o Brasil devia ser sua segunda pátria. Nunca chegou a falar muito bem o português; mas com a sua inteligência, a sua vivacidade natural, exprimia-se fàcilmente, muito embora guardanđo, como diz Andrade Muricy, "o acento o mais pitorescamente germânico possivel". (12).

Sua figura tornou-se popular, em Curitibar; e nos salões mundanos, como nos círculos administrativos, todos o acatavam e procuravam ajudá-lo. Graças à sua energia e às simpatias que inspirava, Kessler imprimiu um grande impulso à vida artística ởa cidade. Trabalhador infatigável, disfarçado, como observa Anđrade Muricy, sob "as aparências do boêmio e do despreocupado" (13), êle foi ao mesmo tempo um realizador e um animador. Procurarei recordar sumàriamente sua ação nos 13 anos que viveu e mourejou em Curitiba.

(10) Op. cit., p. 12 .

(11) Op. cit., p. 9.

(12) Op. cit., p. 32.

(13) Op. cit., p. 31. 
Auguisto Stresser e a ópera "Sidéria"

Comecemos pela apresentação da ópera Sidéria, de seu amigo Augusto Stresser, que tudo deveu ao entusiasmo, à fôrça de vontade e à capacidade artística do músico suíço. Era Augusto Stresser (1872-1918) um compositor amađor, a quem Andrade Muricy reconhecia "imaginação melódica abundante, e algumas vêzes de qualidade rara, conseguindo efeitos ricos pitorescos" (14). Recebera liçōes de música do italiano Aơolfo Coradi e havia de aconselhar-se, também, com Leo Kessler, logo depois de sua chegada a Curitiba. Por essa época Stresser havia composto uma pequena ópera em um ato, cujo libreto, como já disse, fôra escrito por Jaime Balão: a Sidéria. Sidéria era o nome da protagonista, e a ópera relatava uma história de amor desenrolando-se no periodo de lutas revalucionárias que agitaram os Estados meridionais do Brasil nos primeiros anos da República. Não se sentindo com fôrças para orquestrar essa partitura, Stresser submetera-a a Leo Kessler, que logo concebeu o projeto ambicioso de ampliá-la, convertendo-a numa ópera em três atos, que êle mesmo se encarregaria de pôr em cena. Os três parceiros, dois músicos e um poeta, começaram logo a confabular; orientado por Kessler, que tinha boa experiência das coisas do teatro, Jaime Balão refez o libreto, modificanđo cenas já existentes e acrescentanơo outras. A medida que o trabalho prosseguia, Stresser ia compondo novas páginas de partitura, e Kessler também, a tal ponto que a Sidéria ficou sendo mais uma obra de colaboração entre os dois compositores do que uma produção đe Stresser, simplesmente orquestrada por Kessler. É sabido que êste último compôs a ouverture, utilizando temas empregados no decorrer da ópera. Mas na partitura de

(14) Op. cit., p. 26. 
orquestra da Sidéria há outras passagens que são da autoria do musico suiço (15). Tudo isso foi feito num ritmo febril, pois tendo chegado a Curitiba em 1911, já uns poucos meses depois a ópera era posta a ensaiar, sendo apresentada ao público, em espetáculo de gala, no Teatro Guaíra, a 3 de maio do ano seguinte.

Para bem compreender o esfôrço exigido por uma ta! realização, convém lembrar que, dada a falta de recursos de Curitiba, foi preciso contratar em São Paulo e no Rio de Janeiro, cantores e professôres de orquestra para reforçar os elementos locais. Os ensaios foram laboriosíssimos; a montagem exigia providências de tôda espécie. Kessler se multiplicava. Diz Jaime Balão: "era de ver' a ativiałade e a energia com que êle previa e provia a tudo, procurando, reunindo, congregando elementos esparsos de amadores, homens, mulheres, moças, meninas e crianças de diversas raças e procedências - músicos e atores improvisados - uma multidão de pessoas, que se submetiam fielmente ao seu irresistivel império" (16). As autoridades haviam sido generosas, e graças à subvenção concedida pelo govêrno đo Estado foi possível levar a bom têrmo a empreitada. A ópera obteve grande sucesso, sendo cantađa oito vêzes em Curitiba e, segundo Renato Almeida, uma em Ponta Grossa (17). Nessas representaçōes da Sidéria, ao lado de Marieta Bezerra, soprano, que encarnava a protagonista, atuavam o tenor Vucherpfennig, um dos elementos remanescentes da Companhia Papke, que ficara residindo em Curitiba, no papel de Alceu, o amado de Sidéria, e Jorge Leitner no de Juvenal, seu rival no amor e na facção política.

(15) "O jovem e ardoroso maestro, de pleno acőrdo com Stresser pôs-se logo em completa atividade, escrevendo e compondo, sempre de acôrdo e harmonia com Stresser, as partes que faltavam para completar a obra", diz Jaime Balão, rememorando êsse período de sua própria colaboraçāo com Leo Kessler (op. cit., p. 13). Entre os manuscritos de Kessler que examinei em Curitiba, em 1957, encontrei várias páginas destinadas a essa opera.

(16) Op. cit., p. 15.

(17) Renato Almeida, op. cit., p. 418. 


\section{Atividades de Kessler em Curitiba}

Foi no ensino, como era natural, que Leonardo Kessler encontrou, em Curitiba, meios para subsistir. Mas com o entusiasmo sempre pronto a inflamar-se, êle se tornou o elemento catalisador da vida musical da cidade, animando tôàas as suas manifestações, muitas vêzes inventando-as, sempre pronto a colaborar, a dar o melhor de si mesmo .

Logo depois de sua chegada, o Centro Artístico, presidido por Paulo de Assunção, entregou-lhe a direção dos concertos. Com elementos locais Kessler se arranjou para organizar belos programas, improvisando um quarteto de coròas e, quando necessário, uma orquestra. Eram os primeiros concertos sinfônicos que se realizavam em Curitiba, e o público teuto-brasileiro se òeliciava com programas em que Beethoven e Wagner estavam representados. Andrade Muricy, em seu estudo tantas vêzes citado, evoca a figura d’o regente: "O Professor Kessler era ardoroso, até um pouco romântico em seus movimentos, mas a desordem era apenas aparente. Sua verve animada transmitia-se aos executantes; seu entusiasmo era contagioso em extremo. Ele conseguiu, por isso, e com os elementos orquestrais modestíssimos de que dispunha, execuções vivaces e interessantes, senão perfeitas, đe grande número de páginas wagnerianas (sua predileção) e de muitas do repertório clássico e moderno" (18). A 9 de setembro de 1922, no quađro das celebrações đo Centenário da Independência nacional, dirigiu, com a colaboração de Romualdo Suriani, memorável concêrto dedicado aos autores brasileiros, em que figuravam obras de Carlos Gomes, Alberto Nepomuceno e Henrique Oswald, além da sua ouverture para a ópera Sidéria e a Serenata da sua própria ópera Papilio Innocentia, a que me referirei mais adiante (19).

(18) Op. cit., p. 33 .

(19) Nesse programa, que se iniciava com os hinos cívicos e, nāo se sabe muito bem porque, terminava com o Quarteto do Rigoletto, de Verdi, Romualdo Suriani se achava à frente da orquestro para dirigir a Sinfonia da ópera Il Guarany, de Carlos Gomes; todo o resto do programa obedeciı à direção de Kessler. 
Kessler, como já foi öito acima, dedicou-se com afinco ao ensino. Teve inúmeros discípulos, formando tôda uma geração de profissionais e de amadores de música de Curitiba.

Homem de teatro, não abdicou à atividade que tinha sido até então o seu ganha-pão. A guerra fizera desaparecer as companhias de operetas em tournée, que costumavam visitar Curitiba; uma única aparece por aqui, nesse período: a de Platerowski, cujo repertório incluía o Bastien et Bastienne, de Mozart. Leo Kessler organizava suas próprias companhias, arrebanhando elementos locais e desempenhando simultâneamente as funçōes de empresário, diretor de cena e regente de orquestra. Foi assim que montou Im Weissen Roessel, de Eysler, Lehar e Kalman, Ein Walzertraum, de Oscar Straus, e peças àe fundo religioso, como o famoso Mártir do Calvário, de Eduardo Garrido, ou Os Milagres de Santo Antônio, de José braz Martins, música de Ângelo Frondoni. Tôdas essas peças subiram à cena, em Curitiba, durante o ano ẳ 1923, em que desenvolveu particular atividade nesse setor especial.

\section{o Conservatório}

Em 1916 êle havia canalizado a sua atividade didática, fundanåo o Conservatório de Música do Paraná, estabelecique dirigiu até o fim de sua vida. Dispondo de um internato feminino, destinado às alunas procedentes do interior ăo Estado, o Conservatório teve grançe êxito e já no primeiro ano de existência arrolava para mais de 200 estudantes (20). Kessler tinha a seu cargo as classes de piano, órgão, contraponto e composiçāo, sendo coadjuvado pelos professôres Jorge Vucherpfennig (canto), Amélia Henn, Ema Lubrano Franco e Maria José Assunçāo (piano), Ludovico Seyer e Venzeslau Schwansee (violino), Caetano Barletta (violoncelo), Clotário Barbosa (clarinete) e Romualdo Suriani (clarim e cornetim).

Fizeram épaca, em Curitiba, os grandes concertos anuais para audição dos alunos do Conservatório, por vêzes realizz-

(20) A cerimônia de inauguraçāo do Conservatório realivou-se a 1 de julho de 1916. 
dos com o concurso de orquestra. Em 1919, sob seus auspicios, efetuou-se um concurso die valsas.

\section{Casamento}

Poucas semanas antes da inauguração do Conservatório, Leo Kessler havia contraído matrimônio com uma brasileira de Curitiba, filha de pai sueco e de mãe islandesa: Dona Rosa Amália Bengtsson. O enlace ocorreu a 20 de maio de 1916, havendo nasciờ dessa união uma filha, hoje Dona Dorotéa Kessler Ferreira, espôsa do dr. Cid César Ferreira, que tinha apenas três anos quando o pai desapareceu, nas trágicas circunstâncias que passarei a narrar.

\section{Crepúsculo}

Em janeiro de 1924 o violinista brasileiro Peri Machado, que por essa época estava no auge da nomeada, chegava a Curitiba para realizar uma série de concertos. Leo Kessler, excelente pianista, devia acompanhá-lo e, uma vez terminada a série de concertos, em Curitiba, viajar com o violinista, que partia em excursão pelos demais Estados do Sul e Repi: blicas do Prata. Sempre disposto a empreender novas aventuras e certamente seduziơo pela idéia de rever ceniros de cultura musical tão importantes como Buenos Aires e Montevidéu, Kessler aceitara a proposta que lhe havia feito o violinista. Depois do último concêrto em Curitiba, realizado a 4 de fevereiro, os dois artistas partiram. Essa peregrinação artística, todavia, não ơevia terminar bem. Em julho Kessler era acometido de uma crise de depressão nervosa, análoga à que já havia padecido quando tinha dezoito anos e fôra obrigado a interromper os estudos. Segundo certos rumores que correram, na época, e de que se fêz eco o comentarista do jornal A Cidade, de Blumenau, em artigo alusivo 20 seu fale- 
cimento, as causas dêsse distúrbio mental seriam contrariedades que sofreu, no decurso da tournée (21). Falou-se, também, em excessos a que teria sido induzido pelo exemplo de Peri Machado, excelente artista mas incorrigível boêmio. $\mathrm{O}$ fato é que em julho de 1924, em estado de completa alienação mental, Leo Kessler era embarcado, em Monteviơéu, a bordo de um navio que o transportou a Paranaguá, onde a espôsa o aguardava. Viagem trágica; entregue à vigilância da tripulação o pobre demente inspirava os maiores cuidados, temendo-se que em sua inconsciência êle se jogasse ao mar.

Dona Rosa Amália Kessler internou o mariảo no Hospital Santa Isabel, de Blumenau. E ao cabo de dois meses de tratamento êle parecia haver recuperado inteiramente o uso da razão. Os facultativos já se dispunham a restituí-lo à família quando, a 29 de setembro ocorreu o trágico desfecho.

Kessler havia passado todo o dia em companhia da espôsa, que viera de Curtiba para visitá-lo. Recolhendo-se a um hotel da localidade, ao cair da noite, Dona Rosa Amália Kessler deixara o marido entregue às enfermeiras. $\mathrm{Na}$ manhã seguinte constataram que o doente desaparecera, burlan-

(21) "Foi por amor de sua arte - lê-se nesse artigo, assinado por Gomes Winther - que êle, em princíplo déste ano, deixandq as comodidades de seu lar, saiu em excursão artistica com Perı Machado, o maior violinista da América do Sul, que a Kessler ficou devendo o êxito que teve e os aplausos fortes de numerosas platéias. A viagem com Peri Machado pelos Estados do Sul e pelas Repúblicas da Plata marcou o último empreendimento artístico de Leo Kessler. Porque chegando em Montevidéu, minado de desgostos, veio a sofrer um desvio mental e teve de abandonar a sua arte. Atribuem êsse desvio às dificuldades financeiras que o notável pianista teria passado para com sua família, regressou ao Brasil (sic.). Penso que nāo foi essa a causa do declínı daquele artista; Kessler pouco ligava ao dinheiro e, conhecidíssimo em tóda parte, fácil the seria encontrar recursos para se safar de embaraços pecuniários. A causa determinante da moléstia mental que levou Leo Kessler a uma morte trágica foi a desilusāo, a ingratidão. Acompanhando Peri Machado èle viu em Montevidéu que nem sempre uma grande inteligência está ao lado de um grande coraçāo". (A Cidade, Blumenau, 5 de outubro de 1924). 
đơ a vigilância, naturalmente relaxada, dadas as condiçōes satisfatórias em que êle já se encontrava. Galgando o muro do estabelecimento Kessler havia ganho as margens do Itajaí, êsse rio que "imita o Reno" de sua terra natal, conforme o título do famoso romance de Viana Moog. E desaparecera em suas águas, como nas águas lendárias do rio de Lorelei. Roberta Schumann, também agindo inconscientemente, havia procurado a morte, setenta anos antes, em Düsselơorf. Depois de quatro dias de mortal agonia para a sua companheira, o corpo de Leo Kessler, que a correnteza havia arrebatado, foi finalmente encontrado. Afogado nas águas do rio Itajaí êle encontrara a morte duas semanas depois da data do seu quadragésimo aniversário.

Para seu fiel amigo Jaime Balão deixara um bilhete lacônico em que se lê:

"Meu querido Jaime Balão - Estão me faltando as minhas fôrças. Peço procurar obter que o. Estado fique com a minha ópera Inocência, em benefício de minha infeliz filhinha. Lembranças a todo Paraná. Guarda-me bem em teu coração e perdoa-me. Teu infeliz Leo" (22).

\section{Homenagens póstumas}

Sepultados em Blumenau seus despojos foram transladados para o Cemitério de Curitiba em 1928. Na manhã do dia 17 de abril dêsse ano a urna funerária chegava à capital paranaense, sendo solenemente transportada da estação da Estrada de Ferro para o Cemitério, onde falaram Jaime Balão, Domingos Duarte Veloso e o Pastor Berchner. A tarde houve uma sessão em memória do artista, no Teatro Guaíra, sendo auvidas algumas d̉e suas composições, dirigidas por Romualdo Suriani (23).

No dia 10 de novembro o Conservatório de Música do Paraná rendeu homenagem ao seu fundador e Diretor, orga-

(22) Op. cit., p. 45.

(23) Marchas Carlos Cavalcanti e Afonso de Camargo 
nizando no Teatro Guaíra uma sessão em que falaram Samuel César e Paulo de Assunção, sendo ouvidos trechos da ópera Papilio Innocentia cantados pela sua antiga discípula Margarida Silva, estando a orquestra sob a direção do Maestro Stabile. No foyer do Teatro foi inaugurada uma placa de bronze com a seguinte inscrição: "A Leo Kessler, compositor e mestre".

\section{A obra}

Na Europa, como no Brasil, Leo Kessler nunca deixou de compor. Mas sua produção não é extensa. Ele "era caracteristicamente um homem de ação, mais do que um espírito criacor", como diz Andrade Muricy (24). E o grande crítico que - repito - foi um de seus alunos, não the reconhece "a imaginação melódica fácil" (25).

Limitar-me-ei a indicar as suas obras principais, mencionando as circunstâncias em que algumas delas foram compostas. Ả ópera Papilio Innocentia reservarei parágrafo à parte, analisando perfunctòriamente algumas de suas páginas. A lista de composições que se segue não deve ser considerada como exaustiva. Limito-me a indicar aquelas cujas partituras me foi dado compulsar ou acêrca das quais encontrei referências nos escritos de Jaime Balão, de Andrade Muricy, ou em jornais da época.

Absorviało pelos trabalhos didáticos e outros empreendimentos, era geralmente à noite que Leo Kessler compunha. Quando atravessava um período de criação intensiva, como o da gestão de sua ópera, êle sacrificava as horas de sono, trocando o leito pela mesa de trabalho. Na exaltação de que ficava possuído, quedava-se tôda a noite sôbre o pentagrama, assim o surpreendendo, muitas vêzes, a alvorada curitibana.

Antes de transferir-se para o Brasil, como já tive oca-

(24) Op. cit., p. 34

(25) Op. cit., p. 39. 
sião de diizer, Leo Kessler havia composto e publicado algumas de suas composições. Pertencem a êsse período um Quarteto em sol menor, para instrumentos de arco, escrito em Paris, sob os conselhos de Widor; e a já aludida Valse de Concert, para piano.

No Brasil muito provàvelmente sua primeira composição foi a Marcha Triunfal, composta para a cerimônia da posse áo Presidente do Estado do Paraná, General Dr. Carlos Cavalcanti, e executada nésse dia, nos jardins do Congresso Estadual, pela Banda do Regimento de Segurança, sob a direção do autor.

Seguiram-se al ouverture e outros trechos ảa ópera Sidéria, em colaboração com Augusto Stresser. A Marcha Triunfal acima referida devidamente transcrita para orquestra, figurava na partitura dessa ópera.

Por ocasião dos funerais do Coronel João Gualberto Gomes de Sá, morto na campanha do Contestado, foi executaơo um Poema Sinfônico de Leo Kessler; e para a chegada a Curitiba dos despojos de Brasílio Itiberê (primeiro dêsse nome, falecido em 1913) Kessler compôs uma Elegia para soprano solo, côro e orquestra, empreganáo temas extraídos das obras do pranteado diplomata e compositor; a obra foi executada no decurso de uma solenidade musical em que também foram ouvidas várias composiçōes de Brasílio Itiberê.

Leo Kessler escreveu numerosos hinos (entre os quais um intitulaơo Natal, sôbre versos de Carlos R. Moritz, e publicado em Curitiba) e várias canções (algumas com letra de Francisco Leite).

Acrescentarei a essa relação a Marcha Afonso de Camargo que Romualdo Suriani dirigiu por ocasião da homenagem prestada à memória do compositor, no dia 17 de abril ảe 1928. Não encontrei outra referência a essa obra, e não vi a partitura, que a família parece desconhecer. 


\section{A ópera "Papilio Innocentia"}

Em 1912, logo após a memorável apresentação da ópera Sidéria, de Augusto Stresser, em que a sua colaboração fôra tão importante, Leo Kessler concebera o projeto de escrever uma ópera, a sua ópera. Na euforia do sucesso sentia a ambição đảe também ligar o seu nome à música dramática brasileira, produzindo uma partitura sôbre tema nacional e de sabor nacional. Emiliano Perneta, o príncipe dos poetas paranaenses, forneceu-lhe o libreto, inspirado no famoso romance do Visconde de Taunay, Inocência. Com muita habilidade e um senso aguơo das situações dramáticas, Emiliano Perneta condensou em três atos as linhas mestras da narrativa, fazendo alternar com muita felicidade elementos característicos, cômicos, poéticos ou de grande intensidade emocional.

Inocência, obra capital ảa literatura brasileira - que toơo mundo lê aos quinze anos - é a melancólica história de Cirino, esculápio itinerante, e da formosa Inocência, donzela sertaneja, sujeita à férrea autoridade paterna. Admitido a transpor os umbrais do santuário familiar, para medicar a jovem, Cirino cai prisioneiro de seus encantos, senơo correspandido nessa afeição. Pereira, o pai, nada percebe, porque sua atenção fôra desviada pela chegada de um ingênuo naturalista alemão, Meyer, que com a maior simplicidade havia teciơo hinos de admiração à beleza de Inocência; tal procedimento, considerado inadmissivel pelo código sertanejo de boas usanças, tornara suspeito o louro viajante. A inconveniência de Meyer chega ao ponto de dar a uma variedađ̛̉e de borboletas que descobrira, e que o entusiasmava, o nome de Papilio Innocentia, com que será apresentada à Sociedade Geral Entomológica dè seu país natal. Inocência, porém, está prometida ao boiadeiro Manecão Doca, e só a êle pertencerá. Numa casta entrevista noturna, sob as árvores do pomar, Cirino e Inocência examinam a situação desesperada de seus amôres e decidem apelar para o padrinho da jovem, única pessoa sôbre a terra.$c 0 m$ autoriởade para obter de $\mathrm{Pe}$ reira o rompimento da promessa feita a Manecão Doca. Ci- 
rino parte em busca dêsse possivel salvador, cujo sítio se encontra a vários dias de viagem a cavalo do de Pereira. Mas a cena do pomar teve uma testemunha na pessoa do anão Tico, agregado da família, que tudo descobre. O noivo ludibriado, informado da humilhação que lhe é inflingida, sai ao encalço de Cirino e sôbre êle despeja a carga de sua garrucha. Mas nem por isso conquistará a mão de Inocência; ela sucumbe à grande mágoa que d’espedaçou seu coração enamorado.

Para êsse entrecho, agitado pela sôpro veemente de sentimentos puros e fortes, o compositor havia escrito uma partitura em que desde os primeiros compassos da Introdução o tema não caracterizava os amores de Cirino e de Inocência - e mais particularmente personifica Inocência - revela o clima passional do drama.

Esse tema será ouvido nas principais passagens da ópera: primeiro encontro dos dois jovens, visita de Cirino à donzela doente; no $2 .^{\circ}$ ato, aueto no laranjal, cena entre o pai e a filha; no $3 .^{\circ}$ ato, intervenção do padrinho em favor ảos namorados, último dueto de amor e desfecho. No final o compositor faz ouvir integralmente a Introdução.

Outros motivos condutores são empregados, com moderação. O mais insistente é o que parece caracterizar Cirino, envolvido em harmonias wlagnerianas.

E curioso abservar que Leo Kessler, mal chegado ao Brasil (sua ópera foi escrita entre 1912 e 1915), já demonstrava interêsse pela música popular, empregando-a, quando a ação o exigia, em várias cenas. Logo no início encontramos o acalanto da preta velha, Maria Conga, para adormentar Inocência; o camarada de Meyer, o pernóstico José, canta e dança um maxixe carioca, repetido no $2 .^{\circ}$ ato; nesse $2 .^{\circ}$ ato o côro de escravos trabalhando na lavoura entoa uma melodia bem característica.

E no último ato, homenagem ao Paraná, certamente, si- 
tua-se um buliçoso fandango, cantado e dançađo pelos figurantes.

A Papilio Innocentia nunca devia subir à cena; o animador que realizara o milagre de montar a ópera de Augusto Stresser, em Curitiba não teria a dita òe ver a sua própria partitura executada integralmente, com cantores em cena. Sòmente trechos da ópera foram incluídos em programas de concertos, durante a vida de Kessler ou depois de sua morte. Afono'o d'Escragnolle Taunay, filho do escritor, em carta datada de 29 de maio de 1915, o autorizara a utilizar o assunto do romance. Mas os esforços do compositor junto às autoridades visando obter o auxílio finançeiro imprescindível à montagem da ópera não tiveram eco. Leo Kessler havia ardentemente esperado que em 1922 as celebrações do Centenário da Independência do Brasil the oferecessem a desejada oportunidade. Em março de 1920 empreendera mesmo uma viagem a São Paulo, para solicitar o auvio do Presidente do Estado, Altino Arantes, que havia conhecido em Curitiba, por ocasião de uma visita oficial. Mas todos os seus esfurços foram baldados. A morte, em cujos braços êle se atirou inconscientemente, tão moço ainđa, devia fazer cessar as possibilidades sempre latentes de obter, com a sua energia, o seu bom humor e a sua irradiante simpatia, uma ajuda compreensiva das autoridades e đa direção artística đos grandes teatros brasileiros. Naquele tempo não se podia dizer que Curitiba possuísse um "grande teatro". Mas dentro em breve ela o terá, e um dos maiores, e àos mais belos do país. Não seria a soleniđade da sua inauguração o momento propício para tirar do olvido a partitura da Papilio Innocentia, ópera brasileira, de assunto brasileiro, poema de um grande poeta paranaense, música de um suíço que dêste Estado fêz sua segunda pátria, e muitos serviços lhe prestou, com a sua bene. mérita atividade? Que obra teatral seria mais adequada para restituir o tradicional Guaíra à sua missão de escola de alta cultura artística da capital paranaense? Permito-me fazer a sugestāo, acrescentanỏo que a montagem dessa ópera é coisa relativamente fácil, e que bem dirigida, bem posta em cena, 
a Papilio Innocentia reservará uma agradabilíssima surprêsa a todos os que a ouvirem. Porque, pelo libreto e pela partitura é obra realmente concebida para o teatro, com o sentido dos efeitos cênicos que asseguram a êxito de uma ação dramática falada ou cantaỏa.

Seu compositor, em todo caso, não será esquecido; teve um papel na história da vida musical brasileira do século $\mathrm{XX}$. Provam-no as referências bibliográficas citadas no comêço dêste estudo. 